\title{
Oncology patients' perceptions of and experiences with COVID-19
}

\author{
Christine Miaskowski ${ }^{1,2}$ (D) Steven M. Paul ${ }^{1} \cdot$ Karin Snowberg $^{1} \cdot$ Maura Abbott $^{3} \cdot$ Hala Borno $^{2} \cdot$ Susan Chang $^{2}$. \\ Lee May Chen ${ }^{2} \cdot$ Bevin Cohen ${ }^{4}$ B Bruce A. Cooper ${ }^{1} \cdot$ Marilyn J. Hammer $^{5}$ - Stacey A. Kenfield ${ }^{2}$. Angela Laffan ${ }^{2}$. \\ Jon D. Levine ${ }^{2} \cdot$ Rachel Pozzar $^{5} \cdot$ Katy K. Tsai ${ }^{2} \cdot$ Erin L. Van Blarigan ${ }^{2} \cdot$ Katherine Van Loon $^{2}$
}

Received: 17 July 2020 / Accepted: 12 August 2020 / Published online: 18 August 2020

(C) Springer-Verlag GmbH Germany, part of Springer Nature 2020

\begin{abstract}
Purpose No information is available on cancer patients' knowledge of and experiences with COVID-19. We undertook an evaluation of differences in COVID-19 symptom occurrence rates, COVID-19 testing rates, clinical care activities, knowledge of COVID-19, and use of mitigation procedures between patients who were and were not receiving active cancer treatment. Methods Patients enrolled were $\geq 18$ years of age; had a diagnosis of cancer; and were able to complete the emailed study survey online.

Results Of the 174 patients who participated, $27.6 \%(n=48)$ were receiving active treatment, $13.6 \%$ were unemployed because of COVID-19, 12.2\% had been tested for COVID-19, and 0.6\% had been hospitalized for COVID-19. Patients who were not on active treatment reported a higher mean number of COVID-19 symptoms $(3.1( \pm 4.2)$ versus $1.9( \pm 2.6))$, and patients who reported a higher number of COVID-19 symptoms were more likely to be tested. Over 55\% of the patients were confident that their primary care provider could diagnose COVID-19, and the majority of the patients had high levels of adherence with the use of precautionary measures (e.g., social distancing, use of face coverings).

Conclusion The high level of COVID-19 symptoms and the significant overlap of COVID-19 and cancer-related symptoms pose challenges for clinicians who are assessing and triaging oncology patients for COVID-19 testing. For patients on active treatment, clinicians face challenges with how to assess and manage symptoms that, prior to COVID-19, would be ascribed to acute toxicities associated with cancer treatments or persistent symptoms in cancer survivors.
\end{abstract}

Keywords COVID-19 $\cdot$ Cancer $\cdot$ Perceptions $\cdot$ Fears $\cdot$ Mitigation procedures $\cdot$ Symptoms

\section{Introduction}

The emergence of the novel coronavirus SARS-CoV-2 in December 2019, in Wuhan, China [1], dramatically changed the care of oncology patients. While limited data are available on the occurrence of the coronavirus disease 2019 (COVID-

Christine Miaskowski

chris.miaskowski@ucsf.edu

1 Department of Physiological Nursing, School of Nursing, University of California, 2 Koret Way - N631Y, San

Francisco, CA 94143-0610, USA

2 School of Medicine, University of California, San Francisco, CA, USA

3 Columbia University Medical Center, New York, NY, USA

4 Mount Sinai Medical Center, New York, NY, USA

5 Dana Farber Cancer Institute, Boston, MA, USA
19) in cancer patients [2, 3], one study from China reported a history of cancer in 18 of 1590 confirmed cases of COVID-19 [4]. In this study, after adjusting for age, sex, and comorbidities, a cancer diagnosis was associated with an increased risk of developing severe sequelae of COVID-19 (i.e., need for mechanical ventilation, death). In two recent consortium studies of cancer patients with confirmed cases of COVID-19, 13 [5] to $28 \%$ [6] of patients died. Risk factors associated with increased mortality included older age [5, 6], being male [6], presence of comorbidities [5, 6], being a former smoker [5], and having a poorer performance status [5].

The first known case of COVID-19 transmitted by community spread in the USA was reported in Northern California on February 28, 2020 [7]. Given that COVID-19 is transmitted primarily through person-to person contact [8], public health orders were issued to limit person-to-person interaction [9] and to institute mitigation procedures [10]. On March 17, a "shelter in place order" went into effect in San Francisco and five other Bay Area counties [11]. With the issuance of the 
"shelter in place order," for oncology patients, diagnostic and surgical procedures were delayed, treatment plans were altered to minimize visits to the clinic, and routine follow-up visits were postponed.

Evidence from the general population is beginning to emerge on individuals' experiences with and knowledge of COVID-19, as well as on the use of various mitigation procedures. In a study of the general population in China $(n=1210)$ [12], 0.9\% had undergone COVID-19 testing; $60.5 \%$ agreed that COVID-19 was an airborne virus; $46.5 \%$ were very confident in their doctor's ability to diagnose COVID-19; and $59.8 \%$ always wore masks. In another population-based study in the USA $(n=2402)$ based on the data collected in early May many from individuals in New York City, Los Angeles, and a nationwide cohort [13], most of the participants supported stay-at-home orders and nonessential business closures ( $82.6 \%)$. In addition, the majority reported always or often wearing face coverings in public areas $(\sim 84.5 \%)$ and believed that their state's restrictions achieved the right balance $(\sim$ $66.3 \%)$ or were not restrictive enough $(\sim 18.0 \%)$. The authors of both studies noted the importance of evaluating additional groups of individual's knowledge of and experiences with COVID-19. This information can be used to determine patients' educational and clinical needs and to plan appropriate public health interventions.

To date, no information is available on oncology patients' knowledge of and experiences with COVID-19. Given the potential increased risk for serious adverse events associated with COVID-19 infection in oncology patients $[14,15]$ and the changes in clinical practice as a result of the various "shelter in place" orders, we undertook an evaluation of differences in COVID-19 symptom occurrence rates, COVID-19 testing rates, clinical care activities, knowledge of COVID-19, and use of mitigation procedures between patients who were $(n=$ $48)$ and were not $(n=126)$ receiving active cancer treatment.

\section{Methods}

\section{Sample and settings}

Oncology patients were recruited from a registry of individuals who participated in our previous National Cancer Institute-funded symptom management studies (CA187160, CA212064, CA151692) and gave permission to be recontacted for future studies. Potential participants received an email with a brief explanation of the study and a link that directed them to the study's enrollment page. This enrollment page explained the purpose of the study, the timeframe for survey completion, and information about participating in research. This study was exempt from requiring written informed consent by the Institutional Review Board at the University of California, San Francisco (UCSF). Patients were included if they were $>18$ years of age; were able to read, write, and understand English; had a diagnosis of cancer; and were able to complete the study questionnaires online and by completing the survey consented to participate. A total of 627 emails were sent, 250 patients began the survey, and 174 completed the information that is presented in this paper (27.8\% response rate).

\section{Recruitment and survey administration}

Emails were sent to potential participants beginning May 27, 2020. Patients who received the survey link were asked to complete the survey within 2 weeks. After 14 days, one email reminder was sent to the patients who did not respond to the initial request to complete the survey. Responses as of June 19, 2020, are presented in this paper.

Patients were asked to answer all of the survey questions in relationship to their experiences in the past 14 days. The entire survey took $\sim 60 \mathrm{~min}$ to complete. Patients were advised that doing the survey in one sitting was preferable but to take as many breaks as needed. All of the instruments were completed online using Research Electronic Data Capture (REDCap ${ }^{\mathrm{TM}}$ ) $[16,17]$.

\section{Instruments}

Demographic and clinical characteristics-Patients completed a demographic questionnaire (e.g., age, marital status, living arrangements), the Karnofsky Performance Status (KPS) scale [18], and the Self-Administered Comorbidity Questionnaire (SCQ) [19]. In addition, they responded to questions about their cancer diagnosis, previous and current cancer treatments, and presence of metastatic disease.

COVID-19 questionnaire-This investigator-developed questionnaire was modeled after the survey that was used to evaluate symptoms of COVID-19, knowledge of COVID-19, use of precautionary measures for COVID-19, and health care utilization in the general population in China [12].

\section{Data analysis}

Survey responses reside on a UCSF secure server. Data were downloaded from REDCap [16, 17] into the Statistical Package for the Social Sciences (SPSS) Version 27 (IBM Corporation, Armonk, NY) for subsequent analyses. Descriptive statistics for sample characteristics and study measures were calculated and reported as means and standard deviations for quantitative variables and percentages and frequencies for categorical variables. Differences between groups were evaluated using independent sample $t$ tests, chisquare analyses, and Mann-Whitney $U$ tests. A $p$ value of $<$ 0.05 was considered statistically significant. 


\section{Results}

\section{Differences in demographic and clinical characteristics}

Of the 174 patients who participated in this study, $27.6 \%(n=$ 48 ) were receiving active treatment (Table 1 ). No differences were found in any demographic characteristics between patients who were and were not receiving active treatment. The total sample was $98.3 \%$ female, with a mean age of 63.3 ( \pm $11.0)$ years. The majority of the sample was White $(82.2 \%)$, lived in a private home or apartment (98.8\%), was married/ partnered (59.8\%), and had a college degree (77.4\%). In terms of employment status, $40.2 \%$ of the patients were currently employed and $13.6 \%$ were unemployed because of COVID19.

No differences were found in the majority of the clinical characteristics between patients who were and were not receiving active treatment (Table 1). The majority of the patients had breast cancer $(79.6 \%)$ and $25.9 \%$ reported metastatic disease. Compared with the patients who were not receiving active treatment, patients on active treatment had a significantly lower KPS score, a higher level of comorbidity, and a longer time since their cancer diagnosis (all, $\mathrm{p}<0.05$ ).

\section{Differences in COVID-19 symptoms and COVID-19 testing}

In response to the question "During the past 14 days, have you had any of the following symptoms?" on the COVID-19 questionnaire, as shown in Table 2, compared with patients receiving active treatment, patients not on active treatment reported significantly higher occurrence rates for persistent fever, repeated shaking chills, severe chest pain, and ringing in your ears. No differences were found between the two groups in the rates of COVID-19 testing for the patient themselves or individuals who lived with the patient. Only $12.2 \%$ of the sample was tested for COVID-19.

As shown in Table 3, compared with patients who were not tested, patients who were tested reported significantly higher occurrence of rates for persistent fever, chills, repeated shaking with chills, muscle aches, difficulty breathing, dizziness, loss of sense of taste, loss of sense of smell, and severe chest pain. Compared with patients who were not tested, patients who were tested had a significantly higher number of COVID19 symptoms $(p=0.021)$.

\section{Differences in clinical care}

Patients' responses to the question "During the past 14 days, have you done any of the following activities?" are listed in Table 2 . In the total sample, $20.3 \%$ called their primary care provider, $10.4 \%$ called their oncologist, and $7.0 \%$ had a video appointment with their oncologist. Compared with the patients who were not receiving active treatment, a significantly higher percentage of patients on active treatment saw their oncologist in the clinic (i.e., $4.0 \%$ versus $14.6 \%, p=0.021$ ).

\section{Knowledge of COVID-19}

Because no differences were found between the two groups for any of the questions on Table 4, data for the total sample are reported. In terms of viral transmission, while $98.9 \%$ of the patients agreed that COVID-19 was transmitted as droplets when individuals cough or sneeze, only $85.0 \%$ agreed that COVID-19 is an airborne virus. The majority obtained their health information from the Internet (78.7\%) and/or television $(67.2 \%)$. The majority were very $(36.3 \%)$ or somewhat (47.7\%) satisfied with the amount of health information that is available about COVID-19. The majority (55.2\%) were very confident in their primary care provider's ability to recognize and diagnose COVID-19. Thirty-five percent of the sample indicated that they were very $(3.4 \%)$ or somewhat (30.6\%) likely to contract COVID-19 and 33.5\% indicated that they were very likely to survive if infected with the virus. In terms of worries, $19.5 \%$ and $54.6 \%$ were very worried or somewhat worried, respectively, that family members would become infected with COVID-19.

\section{Use of precautionary measures}

Because no differences were found between the two groups on the use of any of the precautionary measures listed on Table 5 , data for the total sample are reported. The majority of the patients reported that they always did the following behaviors: covering mouth when coughing and sneezing; avoiding sharing utensils during meals; washing hands with soap and water; washing hands immediately after coughing, rubbing nose, and/or sneezing; wearing a mask; maintaining social distancing, and washing hands after touching objects that may be contaminated. On average, in the past 14 days, patients stayed at home $18.0( \pm 6.8)$ hours.

\section{Discussion}

This study is the first to report on oncology patients' experiences with and perceptions of COVID-19 in terms of COVID19 symptom occurrence rates, COVID-19 testing rates, clinical care activities, knowledge of COVID-19, and use of mitigation procedures. While one may have hypothesized that a large number of differences would be found in the experiences and perceptions of oncology patients who were and were not receiving active treatment, very few differences were identified. As of June 19, 2020, 3.2 million (8.1\%) of California's population of 39.5 million were tested for COVID-19 (https:// 
Table 1 Differences in patients' demographic and clinical characteristics based on treatment status

\begin{tabular}{|c|c|c|c|c|}
\hline Characteristic & $\begin{array}{l}\text { Total sample } \\
n=174\end{array}$ & $\begin{array}{l}\text { Not on current treatment } \\
n=12672.4 \%\end{array}$ & $\begin{array}{l}\text { Receiving treatment } \\
n=4827.6 \%\end{array}$ & Statistics \\
\hline \multicolumn{5}{|l|}{ Demographic characteristics } \\
\hline Age (years, mean, SD) & $63.3(11.0)$ & $64.2(11.2)$ & $60.9(10.1)$ & $t=1.79, p=0.076$ \\
\hline Female $(\%, n)$ & $98.3(171)$ & $99.2(125)$ & $95.8(46)$ & $\mathrm{FE}, p=0.185$ \\
\hline \multicolumn{5}{|l|}{ Living arrangements $(\%, \mathrm{n})$} \\
\hline Private home or apartment & $98.8(172)$ & $99.2(125)$ & $97.9(47)$ & $X^{2}=3.01, p=0.222$ \\
\hline Assisted living facility & $0.6(1)$ & $0.8(1)$ & $0.0(0)$ & \\
\hline Other & $0.6(1)$ & $0.0(0)$ & $2.1(1)$ & \\
\hline Lives alone ( $\%$ yes, $n$ ) & $31.6(55)$ & $33.3(42)$ & $27.1(13)$ & $\mathrm{FE}, p=0.470$ \\
\hline Married/partnered ( $\%$ yes, $n$ ) & $59.8(104)$ & $58.7(74)$ & $62.5(30)$ & $\mathrm{FE}, p=0.730$ \\
\hline Number of people in your household including yourself (mean, SD) & $1.9(0.9)$ & $1.8(0.9)$ & $2.1(0.9)$ & $t=1.45, p=0.150$ \\
\hline \multicolumn{5}{|l|}{ Race/ethnicity } \\
\hline White & $82.2(143)$ & $85.6(108)$ & $72.9(35)$ & $X^{2}=9.48, p=0.050$ \\
\hline Black or African American & $1.1(2)$ & $1.6(2)$ & $0.0(0)$ & \\
\hline Asian or Pacific Islander & $6.9(12)$ & $4.8(6)$ & $12.5(6)$ & \\
\hline Hispanic & $4.6(8)$ & $2.4(3)$ & $10.4(5)$ & \\
\hline Mixed ethnic background and other & $5.2(9)$ & $5.6(7)$ & $4.2(2)$ & \\
\hline \multicolumn{5}{|l|}{ Highest level of education } \\
\hline High school & $2.9(5)$ & $3.2(4)$ & $2.1(1)$ & $U, p=0.818$ \\
\hline Some college & $19.7(34)$ & $19.2(24)$ & $20.8(10)$ & \\
\hline College graduate & $24.3(42)$ & $24.0(30)$ & $25.0(12)$ & \\
\hline Some graduate school & $15.6(27)$ & $15.2(19)$ & $16.7(8)$ & \\
\hline Advanced degree & $37.5(65)$ & $38.4(48)$ & $35.4(17)$ & \\
\hline \multicolumn{5}{|l|}{ Annual household income } \\
\hline$<\$ 20,000$ & $5.5(8)$ & $6.6(7)$ & $2.5(1)$ & $U, p=0.379$ \\
\hline$\$ 20,000$ to $\$ 59,000$ & $26.0(38)$ & $27.4(29)$ & $22.5(9)$ & \\
\hline$\$ 60,000$ to $\$ 100,000$ & $21.9(32)$ & $20.8(22)$ & $25.0(10)$ & \\
\hline$>\$ 100,000$ & $46.6(68)$ & $45.2(48)$ & $50.0(20)$ & \\
\hline Currently employed ( $\%$ yes, $n$ ) & $40.2(70)$ & $39.7(20)$ & $41.7(20)$ & $\mathrm{FE}, p=0.863$ \\
\hline Unemployed because of COVID-19 (\% yes, $n$ ) & $13.6(14)$ & $15.8(12)$ & $7.4(2)$ & $\mathrm{FE}, p=0.346$ \\
\hline \multicolumn{5}{|l|}{ Clinical characteristics } \\
\hline Body mass index $\left(\mathrm{kg} / \mathrm{m}^{2}\right.$, mean, $\left.\mathrm{SD}\right)$ & $26.6(5.4)$ & $26.1(4.8)$ & $27.8(6.7)$ & $t=1.55, p=0.126$ \\
\hline Karnofsky Performance Status score (mean, SD) & $92.4(9.3)$ & $93.5(8.4)$ & $89.6(10.7)$ & $t=2.54, p=0.012$ \\
\hline Number of comorbidities (mean, SD) & $1.6(1.4)$ & $1.5(1.4)$ & $1.9(1.4)$ & $t=-1.35, p=0.179$ \\
\hline Self-Administered Comorbidity Questionnaire score (mean, SD) & $3.3(3.0)$ & $3.0(2.9)$ & $4.1(3.3)$ & $t=-2.14, p=0.034$ \\
\hline \multicolumn{5}{|l|}{ Chronic conditions $(\%, \mathrm{n})$} \\
\hline Heart disease & $7.0(12)$ & $8.0(10)$ & $4.3(2)$ & FE, $p=0.518$ \\
\hline High blood pressure & $29.7(51)$ & $32.3(40)$ & $22.9(11)$ & $\mathrm{FE}, p=0.267$ \\
\hline Lung disease & $5.9(10)$ & $6.4(8)$ & $4.4(2)$ & $\mathrm{FE}, p=1.000$ \\
\hline Diabetes & $4.1(7)$ & $3.2(4)$ & $6.5(3)$ & $\mathrm{FE}, p=0.390$ \\
\hline Ulcer or stomach disease & $3.5(6)$ & $3.2(4)$ & $4.3(2)$ & $\mathrm{FE}, p=0.662$ \\
\hline Kidney disease & $1.8(3)$ & $2.4(3)$ & $0.0(3)$ & $\mathrm{FE}, p=0.568$ \\
\hline Liver disease & $1.8(3)$ & $0.8(1)$ & $4.4(2)$ & $\mathrm{FE}, p=0.177$ \\
\hline Anemia or blood disease & $2.4(4)$ & $1.6(2)$ & $4.5(2)$ & $\mathrm{FE}, p=0.286$ \\
\hline Depression & $26.6(45)$ & $23.8(29)$ & $34.0(16)$ & $\mathrm{FE}, p=0.180$ \\
\hline Osteoarthritis, degenerative arthritis & $28.7(49)$ & $26.2(33)$ & $35.6(16)$ & $\mathrm{FE}, p=0.253$ \\
\hline Back pain & $32.4(55)$ & $32.5(40)$ & $31.9(15)$ & $\mathrm{FE}, p=1.000$ \\
\hline Rheumatoid arthritis & $4.3(7)$ & $5.0(6)$ & $2.3(1)$ & $\mathrm{FE}, p=0.675$ \\
\hline \multicolumn{5}{|l|}{ Cancer diagnosis $(\%, \mathrm{n})$} \\
\hline Breast cancer & $79.6(137)$ & $75.2(94)$ & $91.5(43)$ & $\mathrm{FE}, p=0.111$ \\
\hline Gastrointestinal & $3.5(6)$ & $4.0(5)$ & $2.1(1)$ & \\
\hline Lung & $0.6(1)$ & $0.8(1)$ & $0.0(0)$ & \\
\hline Malignant melanoma & $0.6(1)$ & $0.8(1)$ & $0.0(0)$ & \\
\hline Gynecological & $5.2(9)$ & $7.2(9)$ & $0.0(0)$ & \\
\hline Prostate & $0.6(1)$ & $0.0(0)$ & $2.1(1)$ & \\
\hline Multiple cancer diagnoses or other & $9.9(17)$ & $12.0(15)$ & $4.3(2)$ & \\
\hline Presence of metastatic disease (\% yes, $\mathrm{n})$ & $25.9(44)$ & $23.6(29)$ & $31.9(15)$ & $\mathrm{FE}, p=0.328$ \\
\hline Time since cancer diagnosis (years, mean, SD) & $9.5(6.7)$ & $11.0(7.1)$ & $5.3(3.0)$ & $t=7.28, p<0.001$ \\
\hline Number of previous cancer treatments (mean, SD) & $3.0(1.0)$ & $2.9(0.9)$ & $3.3(1.2)$ & $t=-1.85, p=0.068$ \\
\hline Number of current cancer treatments (mean, SD) & -- & -- & $1.04(0.4)$ & -- \\
\hline Receiving cancer treatments currently $(\%, \mathrm{n})$ & $27.6(48)$ & & & \\
\hline \multicolumn{5}{|l|}{ Types of current treatments (for $n=48 ; \%, n$ ) } \\
\hline Radiation therapy & $4.2(2)$ & & & \\
\hline Chemotherapy & $14.6(7)$ & & & \\
\hline Hormonal therapy & $81.3(39)$ & & & \\
\hline Immunotherapy & $4.2(2)$ & & & \\
\hline Targeted therapy & $0.0(0)$ & & & \\
\hline
\end{tabular}

FE Fisher's Exact test, $\mathrm{kg}$ kilograms, $\mathrm{m}^{2}$ meters squared, $S D$ standard deviation, $U$ Mann-Whitney $U$ test 
covidtracking.com/data/state/california\#historical). In our study, a slightly higher percentage $(12.2 \%)$ of the patients were tested and only one patient $(0.6 \%)$ reported being hospitalized for the infection.

While in a recent report of 350 patients in the USA who tested positive for the infection [20] the median number of symptoms out of 17 was 7 (range 4-10), in our sample, the median number of symptoms out of 15 was 2.0 (range 0 to 15). However, for four of the fifteen COVID-19 symptoms evaluated (i.e., persistent fever, repeated shaking chills, severe chest pain, ringing in your ears), patients not on active treatment reported higher occurrence rates. Equally noteworthy is the relatively high occurrence rates for many of the COVID19-related symptoms among the total sample. For example, symptoms like headache, muscle aches, severe fatigue or tiredness, and difficulty with word finding that are on the list of COVID-19-related symptoms are common symptoms associated with cancer and its treatment [21,22]. This significant overlap of COVID-19 and cancer-related symptoms poses challenges for clinicians who are assessing and triaging oncology patients for COVID-19 testing. Moreover, for patients on active treatment, clinicians face challenges with how to assess and manage symptoms that, prior to COVID-19, would be ascribed to acute toxicities associated with cancer treatments or persistent symptoms in cancer survivors.

Not surprising, patients in our sample who were tested for COVID-19 reported a higher median number of symptoms (i.e., 3 ; range 0 to 15 ). Symptoms with occurrence rates above $70 \%$ in the tested group included persistent fever, chills, repeated shaking chills, loss of sense of taste, and severe chest pain. Again, while only one case of COVID-19 was diagnosed in the 21 patients who were tested, this list of symptoms often suggests the occurrence of an infection or sepsis in an oncology patient that warrants emergency management.

While the number of telehealth visits has increased during the pandemic [23] and international oncology guidelines suggest that telemedicine needs to be considered to support patients and reduce oncology patients' exposure to COVID-19 [24], little is known about how oncology patients have accessed healthcare during the pandemic. As shown in Table 2 , only $20.3 \%$ of our sample contacted their primary care provider and only $10.4 \%$ contacted their oncologist. Except for a higher rate of oncology-related clinic visits in the active treatment group, no differences were found between the treatment groups in the utilization of other clinical care services. As routine healthcare services begin to resume, clinicians will need to consider how they can provide primary care and oncology services to patients in the safest and most cost effective manner [25].

In terms of oncology patients' knowledge and feelings regarding COVID-19 (Table 4), the only comparative data are from a study of the general population in China [12]. While $58.2 \%$ of the Chinese participants were college students, their responses are very similar to our cancer patients. A few findings warrant consideration as public health programs are planned and implemented to improve patients' knowledge and decrease fears regarding the pandemic. While $60.5 \%$ of Chinese participants agreed with the statement that COVID19 is an airborne virus, $85 \%$ of our patients endorsed this statement. This difference may be attributable to when the questionnaires were administered as dissemination of information about the pandemic increases over time.

In contrast to $93.5 \%$ of Chinese participants who obtained health information about the pandemic from the Internet, our patients used multiple sources for information (e.g., Internet, television). It should be noted that the majority of our patients, as well as the Chinese participants, were satisfied with the amount of health information available and confident in their primary care provider's ability to recognize and diagnose the infection. However, over a third of the participants in both studies expressed concerns about themselves or a family member contracting COVID-19. Given the added stress associated with social distancing and other mitigation procedures initiated during the pandemic, clinicians need to be mindful of oncology patients' fears and concerns about COVID-19 as well as plans to monitor and manage their cancer [26] and plan to discuss these concerns during telehealth or in person visits. In addition, given that our patients were well educated, future studies need to evaluate gaps in knowledge and optimal educational approaches for individuals with lower levels of education.

Consistent with the previous reports [12, 13], our patients reported high levels of adherence with the precautionary measures listed on Table 5. These high levels of adherence may be related to the issuance of an executive order in the State of California regarding shelter in place on March 19, 2020 (https://www.gov.ca.gov/ 2020/03/19/governor-gavin-newsom-issues-stay-at-homeorder/), and recommendations by the California Department of Health on the use of face coverings on April 1, 2020 (https://www.cdph.ca.gov/Programs/CID/ DCDC/Pages/Face-Coverings-Guidance.aspx). In addition, these high levels of adherence may be related to oncology patients' concerns about increased risk for adverse events associated with COVID-19 infection.

While this study provides the first information on oncology patients experiences with COVID-19, several limitations warrant consideration. Given that the majority of the patients were well-educated, White women with breast cancer, our findings may not generalize to men, to different racial/ethnic groups, patients with other types of cancer, and/or patients with a lower socioeconomic status. In addition, given that only $27.6 \%$ of the patients were receiving active treatment at the time they completed the survey, 
Table 2 Differences in COVID-19 symptoms and cancer and non-cancer treatments based on treatment status

\begin{tabular}{|c|c|c|c|c|}
\hline Characteristic & $\begin{array}{l}\text { Total sample } \\
n=174 \\
\%(n)\end{array}$ & $\begin{array}{l}\text { Not on current treatment } \\
n=126 \\
72.4 \% \\
\%(n)\end{array}$ & $\begin{array}{l}\text { Receiving } \\
\text { treatment } \\
n=48 \\
27.6 \% \\
\%(n)\end{array}$ & Statistics \\
\hline \multicolumn{5}{|c|}{ COVID-19 symptoms - During the past 14 days, have you had any of the following symptoms? (\% yes) } \\
\hline Persistent fever $\left(>38^{\circ} \mathrm{C}\right.$ of $\left.100.4^{\circ} \mathrm{F}\right)$ for at least one day & $9.2(16)$ & $12.0(15)$ & $2.1(1)$ & FE, $p=0.044$ \\
\hline Chills & $9.9(17)$ & $12.1(15)$ & $4.2(2)$ & FE, $p=0.158$ \\
\hline Repeated shaking with chills & $9.8(17)$ & $12.8(16)$ & $2.1(1)$ & FE, $p=0.043$ \\
\hline Headache & $30.6(53)$ & $32.8(41)$ & $25.0(12)$ & $\mathrm{FE}, p=0.361$ \\
\hline Muscle aches & $33.5(58)$ & $32.0(40)$ & $37.5(18)$ & $\mathrm{FE}, p=0.590$ \\
\hline Cough & $23.7(41)$ & $25.6(32)$ & $18.8(9)$ & $\mathrm{FE}, p=0.426$ \\
\hline Difficulty breathing & $13.8(24)$ & $16.7(21)$ & $6.3(3)$ & $\mathrm{FE}, p=0.088$ \\
\hline Dizziness & $20.2(35)$ & $21.6(27)$ & $16.7(8)$ & $\mathrm{FE}, p=0.532$ \\
\hline Sore throat & $17.5(30)$ & $21.0(26)$ & $8.5(4)$ & $\mathrm{FE}, p=0.071$ \\
\hline Loss of sense of taste & $11.6(20)$ & $13.7(17)$ & $6.3(3)$ & $\mathrm{FE}, p=0.197$ \\
\hline Loss of sense of smell & $12.8(22)$ & $15.2(19)$ & $6.4(3)$ & $\mathrm{FE}, p=0.198$ \\
\hline Severe fatigue or tiredness & $24.4(42)$ & $25.6(32)$ & $21.3(10)$ & $\mathrm{FE}, p=0.691$ \\
\hline Severe chest pain & $9.8(17)$ & $12.8(16)$ & $2.1(1)$ & $\mathrm{FE}, p=0.043$ \\
\hline Difficulty finding the right words in a conversation & $24.0(41)$ & $26.0(32)$ & $18.8(9)$ & $\mathrm{FE}, p=0.426$ \\
\hline Ringing in your ears & $29.4(50)$ & $35.2(43)$ & $14.6(7)$ & $\mathrm{FE}, p=0.009$ \\
\hline $\begin{array}{l}\text { Number of COVID-19 symptoms (mean, SD) } \\
\text { Median number of COVID-19 symptoms }\end{array}$ & $\begin{array}{l}2.8(3.8) \\
2.0\end{array}$ & $\begin{array}{l}3.1(4.2) \\
2.0\end{array}$ & $\begin{array}{l}1.9(2.6) \\
1.0\end{array}$ & $\mathrm{U}, p=0.174$ \\
\hline \multicolumn{5}{|l|}{ COVID-19 testing } \\
\hline \multicolumn{5}{|l|}{ Have you been tested for COVID-19? } \\
\hline $\begin{array}{l}\text { No } \\
\text { Yes and tested negative }\end{array}$ & $\begin{array}{l}87.8(152) \\
11.6(20)\end{array}$ & $\begin{array}{l}87.3(110) \\
11.9(15)\end{array}$ & $\begin{array}{l}89.4(42) \\
10.6(5)\end{array}$ & \multirow[t]{3}{*}{$X^{2}=0.44, p=0.804$} \\
\hline Yes and tested positive & $0.0(0)$ & $0.0(0)$ & $0.0(0)$ & \\
\hline Yes and prefer not to report my test results & $0.6(1)$ & $0.8(1)$ & $0.0(0)$ & \\
\hline \multicolumn{5}{|l|}{ Has anyone you live with been tested for COVID-19? } \\
\hline $\begin{array}{l}\text { No } \\
\text { Yes and tested negative }\end{array}$ & $\begin{array}{l}83.9(146) \\
4.0(7)\end{array}$ & $\begin{array}{l}84.1(106) \\
3.2(4)\end{array}$ & $\begin{array}{l}83.3(40) \\
6.3(3)\end{array}$ & \multirow[t]{4}{*}{$X^{2}=0.97, p=0.616$} \\
\hline Yes and tested positive & $0.0(0)$ & $0.0(0)$ & $0.0(0)$ & \\
\hline Yes and prefer not to report my test results & $0.0(0)$ & $0.0(0)$ & $0.0(0)$ & \\
\hline I live alone & $12.1(21)$ & $12.7(16)$ & $10.4(5)$ & \\
\hline \multicolumn{5}{|c|}{ Clinical care-During the past 14 days, have you done any of the following activities? (\% yes) } \\
\hline Called your primary care provider & $20.3(35)$ & $22.4(28)$ & $14.9(7)$ & FE, $p=0.395$ \\
\hline Seen your primary care provider in the clinic & $6.4(11)$ & $4.9(6)$ & $10.4(5)$ & $\mathrm{FE}, p=0.295$ \\
\hline Had a video appointment with your primary care provider & $12.1(21)$ & $11.1(14)$ & $14.9(7)$ & FE, $p=0.601$ \\
\hline Called your oncologist & $10.4(18)$ & $10.3(13)$ & $10.6(5)$ & $\mathrm{FE}, p=1.000$ \\
\hline Seen your oncologist in the clinic & $6.9(12)$ & $4.0(5)$ & $14.6(7)$ & FE, $p=0.021$ \\
\hline Had a video appointment with your oncologist & $7.0(12)$ & $4.8(6)$ & $13.0(6)$ & FE, $p=0.088$ \\
\hline Received supportive care (e.g., blood transfusion) & $2.9(5)$ & $1.6(2)$ & $6.4(3)$ & FE, $p=0.128$ \\
\hline Received treatment for symptoms (e.g., pain, nausea) & $6.4(11)$ & $4.0(5)$ & $12.8(6)$ & FE, $p=0.072$ \\
\hline Had a nurse visit your home & $1.7(3)$ & $1.6(2)$ & $2.1(1)$ & FE, $p=1.000$ \\
\hline Had an aid care for you in your home & $1.2(2)$ & $0.8(1)$ & $2.1(1)$ & $\mathrm{FE}, p=0.473$ \\
\hline Been hospitalized for COVID-19 & $0.6(1)$ & $0.8(1)$ & $0.0(0)$ & $\mathrm{FE}, p=1.000$ \\
\hline Been hospitalized for cancer care & $0.6(1)$ & $0.8(1)$ & $0.0(0)$ & $\mathrm{FE}, p=1.000$ \\
\hline Have you had medical insurance coverage during the last 14 days & $97.7(169)$ & $96.8(121)$ & $100.0(48)$ & $\mathrm{FE}, p=0.577$ \\
\hline
\end{tabular}

FE Fisher's Exact test, $S D$ standard deviation, $U$ Mann-Whitney $U$ test 
Table 3 Relationship between COVID-19 symptoms and COVID-19 testing

COVID-19 symptoms - during the past 14 days have you had any of the following symptoms?

Not tested

Persistent fever $\left(>38^{\circ} \mathrm{C}\right.$ of $\left.100.4^{\circ} \mathrm{F}\right)$ for at least 1 day

No

Yes

Chills

No

Yes

Repeated shaking with chills

No

Yes

Headache

No

Yes

Muscle aches

No

Yes

Cough

No

Yes

Difficulty breathing

No

Yes

Dizziness

No

Yes

Sore throat

No

Yes

Loss of sense of taste

No

Yes

Loss of sense of smell

No

Yes

Severe fatigue or tiredness

No

Yes

Severe chest pain

No

Yes

Difficulty finding the right words in a conversation

No

Yes

Ringing in your ears

No

Yes

Number of COVID-19 symptoms (mean, SD)

Median number of COVID-19 symptoms

\begin{tabular}{|c|c|c|}
\hline 92.7 (140) & $76.2(16)$ & 0.030 \\
\hline $7.3(11)$ & $23.8(5)$ & \\
\hline 92.7 (139) & $71.4(15)$ & 0.009 \\
\hline $7.3(11)$ & $28.6(6)$ & \\
\hline 92.1 (139) & $76.2(16)$ & 0.039 \\
\hline $7.9(12)$ & $23.8(5)$ & \\
\hline 70.9 (107) & $57.1(12)$ & 0.215 \\
\hline $29.1(44)$ & $42.9(9)$ & \\
\hline $69.5(105)$ & $42.9(9)$ & 0.025 \\
\hline $30.5(46)$ & $57.1(12)$ & \\
\hline 77.5 (117) & $66.7(14)$ & 0.282 \\
\hline $22.5(34)$ & $33.3(7)$ & \\
\hline 89.5 (136) & 61.9 (13) & 0.003 \\
\hline $10.5(16)$ & $38.1(8)$ & \\
\hline 83.4 (126) & $52.4(11)$ & 0.002 \\
\hline $16.6(25)$ & $47.6(10)$ & \\
\hline $4.6(126)$ & $66.7(14)$ & 0.063 \\
\hline $15.4(23)$ & $33.3(7)$ & \\
\hline 90.7 (136) & $71.4(15)$ & 0.021 \\
\hline $9.3(14)$ & $28.6(6)$ & \\
\hline 90.1 (136) & $65.0(13)$ & 0.006 \\
\hline $9.9(15)$ & $35.0(7)$ & \\
\hline 78.0 (117) & $57.1(12)$ & 0.055 \\
\hline $22.0(33)$ & $42.9(9)$ & \\
\hline $92.7(140)$ & $71.4(15)$ & 0.008 \\
\hline $7.3(11)$ & $28.6(6)$ & \\
\hline 76.7 (115) & 70.0 (14) & 0.579 \\
\hline $23.2(35)$ & $30.0(6)$ & \\
\hline 72.3 (107) & $57.1(12)$ & 0.201 \\
\hline $27.7(41)$ & $42.9(9)$ & \\
\hline $2.4(3.4)$ & $5.3(5.6)$ & $0.021^{+}$ \\
\hline 1.5 & 3.0 & \\
\hline
\end{tabular}

*Fisher's Exact test

${ }^{+}$Mann-Whitney $U$ test

$S D$ standard deviation $\%(n)$

Tested

$\%(n)$

09

039

215

$70.9(107) \quad 57.1(12)$

0.025

$69.5(105)$

$42.9(9)$

0.282

77.5 (117)

66.7 (14)

003

$89.5(136)$

61.9 (13)

0.002

83.4 (126)

$52.4(11)$

0.063

4.6 (126)

$66.7(14)$

.

90.7 (136)

$71.4(15)$

.021

$65.0(13)$

0.006

$90.1(136)$

$35.0(7)$

7.1 (12)

0.055

$78.0(117)$

42.9 (9)

0.008

.7 (140)

$71.4(15)$

.579

76.7 (115)

70.0 (14)

.201

$.021^{+}$

1.5
$5.3(5.6)$
3.0 $p$ value* 
Table 4 Knowledge and feelings regarding COVID-19 $(n=174)$

Questions

COVID-19 is transmitted as droplets when individuals cough or sneeze

Agree

Disagree

Don't know

COVID-19 is transmitted by contaminated objects

Agree 75.8

Disagree

7.5

Don't know

COVID-19 is an airborne virus

Agree

Disagree

8.7

Don't know

Have you kept track of the number of individuals in the United States who are infected with COVID-19? (\% yes)

Have you kept track of the number of individuals in the United States who have died from COVID-19? (\% yes)

Have you heard that the number of individuals who have recovered from COVID-19 has increased? (\% yes)

What is your main source of health information? (check all that apply)

Internet

Television

Radio

Family members

Other

What is your level of satisfaction with the amount of health information that is available about COVID-19?

Very satisfied

Somewhat satisfied

Not very satisfied

Not satisfied at all

Do not know

What is your level of confidence in your primary care provider's ability to recognize and diagnosis COVID-19?

Very confident

Somewhat confiden

Not very confident

Not confident at all

Do not know

What do you think is your likelihood of contracting COVID-19 during the current outbreak?

Very likely

Somewhat likely

Not very likely

Not at all likely

Do not know

What do you think is your likelihood of surviving if infected with COVID-19?

Very likely

Somewhat likely

Not very likely

Not at all likely

Do not know

How worried are you that members of your family will become infected with COVID-19?

Very worried

Somewhat worried

Not very worried

Not worried at all

Do not know

How worried are you that your children or grandchildren younger than 16 years of age will become infected with COVID-19?

Very worried

additional research is needed to evaluate the impact of the pandemic on the receipt of primary and cancer care services. Equally important is a need to understand why the patients not receiving active treatment reported more symptoms than the patients on active treatment and why the testing rates were relatively low in this sample. Qualitative 
Table 5 Use of precautionary measures $(n=174)$

How often have you used each of the precautionary measures in the past 14 days?

\begin{tabular}{lllll}
$\begin{array}{l}\text { Never } \\
\%\end{array}$ & $\begin{array}{l}\text { Occasionally } \\
\%\end{array}$ & $\begin{array}{l}\text { Sometimes } \\
\%\end{array}$ & $\begin{array}{l}\text { Most of the } \\
\text { time } \%\end{array}$ & $\begin{array}{l}\text { Always } \\
\%\end{array}$ \\
\hline 0.0 & 0.0 & 0.6 & 14.4 & 85.0 \\
5.2 & 1.7 & 4.6 & 17.2 & 71.3 \\
0.0 & 0.0 & 1.2 & 11.0 & 87.8 \\
2.3 & 3.5 & 14.0 & 27.3 & 52.9 \\
1.7 & 1.2 & 7.5 & 21.4 & 68.2 \\
0.0 & 0.0 & 1.2 & 28.9 & 69.9 \\
0.6 & 0.0 & 2.9 & 17.9 & 78.6 \\
48.5 & 8.2 & 15.8 & 5.8 & 21.7 \\
47.7 & 20.3 & 19.8 & 8.1 & 4.1
\end{tabular}

Covering mouth when coughing and sneezing

Avoiding sharing utensils during meals

Washing hands with soap and water

Washing hands immediately after coughing, rubbing nose, and/or sneezing

Wearing a mask outside regardless of the presence or absence of symptoms

Maintaining social distancing of at least $6 \mathrm{ft}$

Washing hands after touching objects that may be contaminated

Wearing gloves when shopping

20.3

19.8

4.1 pandemic

Over the past 14 days, please let us know the average number of hours per day you have 18.0 (6.8)

stayed at home to avoid COVID-19 (mean, SD)

$S D$ standard deviation

studies are warranted to understand these findings. Given the study's cross-sectional design, future studies need to evaluate for changes in patients' experiences with COVID-19 and cancer care in the context of the evolving pandemic. Equally important and is currently being undertaken by our research team, regional variations in patients' experiences with COVID-19 and cancer care warrant investigation.

Despite these limitations, this study provides information that clinicians can use to educate oncology patients regarding the mechanisms of viral transmission and the need for mitigation procedures, as well as begin discussions about their concerns regarding the likelihood of viral infection, how to assess and report symptoms during and after treatment, and how to re-engage in their care in the safest way possible. In addition, detailed information needs to be provided to oncology patients on multiple platforms (e.g., Internet, television) about the relationships between the risks associated with COVID-19 and cancer screening, treatments, and ongoing surveillance.

Availability of data Data will be provided to the publisher after they obtain a material transfer agreement from the University of California, San Francisco. Individuals who would like a copy of the survey can contact the corresponding author.

Authors' contributions All of the authors participated in the revisions to this paper, the interpretation of the results, and approved the final paper.

Funding information Dr. Miaskowski is an American Cancer Society Clinical Research Professor. Dr. Van Blarigan is funded by CA197077. Dr. Kenfield is funded by the Helen Diller Family Chair in Population Science for Urologic Cancer.

\section{Compliance with ethical standards}

Conflicts of interest The authors declare that they have no conflicts of interest.
Ethics approval This study was approved by the Committee on Human Research at the University of California.

Consent to participate This study was exempted from written informed consent.

Consent for publication All of the authors read the final version of the paper and approved its submission for publication.

\section{References}

1. Chen N, Zhou M, Dong X, Qu J, Gong F, Han Y, Qiu Y, Wang J, Liu Y, Wei Y, Xia J, Yu T, Zhang X, Zhang L (2020) Epidemiological and clinical characteristics of 99 cases of 2019 novel coronavirus pneumonia in Wuhan, China: a descriptive study. Lancet 395(10223):507-513. https://doi.org/10.1016/ s0140-6736(20)30211-7

2. Robinson AG, Gyawali B, Evans G (2020b) COVID-19 and cancer: do we really know what we think we know? Nat Rev Clin Oncol 17(7):386-388. https://doi.org/10.1038/s41571-020-0394-y

3. Robinson A, Gyawali B, Booth CM (2020a) Risk of COVID-19 in patients with cancer. JAMA Oncol. https://doi.org/10.1001/ jamaoncol.2020.2586

4. Liang W, Guan W, Chen R, Wang W, Li J, Xu K, Li C, Ai Q, Lu W, Liang H, Li S, He J (2020) Cancer patients in SARS-CoV-2 infection: a nationwide analysis in China. Lancet Oncol 21(3):335337. https://doi.org/10.1016/s1470-2045(20)30096-6

5. Kuderer NM, Choueiri TK, Shah DP, Shyr Y, Rubinstein SM, Rivera DR, Shete S, Hsu CY, Desai A, de Lima Lopes G Jr, Grivas P, Painter CA, Peters S, Thompson MA, Bakouny Z, Batist G, Bekaii-Saab T, Bilen MA, Bouganim N, Larroya MB, Castellano D, Del Prete SA, Doroshow DB, Egan PC, Elkrief A, Farmakiotis D, Flora D, Galsky MD, Glover MJ, Griffiths EA, Gulati AP, Gupta S, Hafez N, Halfdanarson TR, Hawley JE, Hsu E, Kasi A, Khaki AR, Lemmon CA, Lewis C, Logan B, Masters T, McKay RR, Mesa RA, Morgans AK, Mulcahy MF, Panagiotou OA, Peddi P, Pennell NA, Reynolds K, Rosen LR, Rosovsky R, Salazar M, Schmidt A, Shah SA, Shaya JA, Steinharter J, StockerlGoldstein KE, Subbiah S, Vinh DC, Wehbe FH, Weissmann LB, Wu JT, Wulff-Burchfield E, Xie Z, Yeh A, Yu PP, Zhou AY, Zubiri L, Mishra S, Lyman GH, Rini BI, Warner JL, Covid CC 
(2020) Clinical impact of COVID-19 on patients with cancer (CCC19): a cohort study. Lancet 395(10241):1907-1918. https:// doi.org/10.1016/S0140-6736(20)31187-9

6. Lee LYW, Cazier JB, Starkey T, Turnbull CD, Team UKCCMP, Kerr R, Middleton G (2020) COVID-19 mortality in patients with cancer on chemotherapy or other anticancer treatments: a prospective cohort study. Lancet 395(10241):1919-1926. https://doi.org/ 10.1016/S0140-6736(20)31173-9

7. Moon S (2020) The CDC has changed the criteria for testing patients with corona virus after the first case of unknown origin was confirmed. CNN. https://www.cnn.com/2020/02/27/health/uscases-coronavirus-community-transmission/index.html.

8. CDC (2020a) How COVID-19 spreads. CDC, Atlanta, GA https:// www.cdc.gov/coronavirsu/2019-ncov/prevent-getting-sick/howcovid-spreads.html

9. CDC (2020b) Social distancing. CDC, Atlanta, GA https://www. cdc.gov/coronavirus/2019-ncov/prevent-getting-sick/socialdistancing.html

10. CDC (2020c) Implementation of mitigation strategies for communities with local COVID-19 transmission. CDC, Atlanta, GA, https://www.cdc.gov/coronavirus/2019-ncov/community/ community-mitigation.html

11. Allday E (2020) Bay Area orders "shelter in place," only essential businesses open in 6 counties. 2020, https://www.sfchronicle.com/ local-politics/article/Bay-Area-must-shelter-in-place-Only15135014.php

12. Wang C, Pan R, Wan X, Tan Y, Xu L, Ho CS, Ho RC (2020) Immediate psychological responses and associated factors during the initial stage of the 2019 Coronavirus Disease (COVID-19) epidemic among the general population in china. Int $\mathrm{J}$ Environ Res Public Health 17(5). https://doi.org/10.3390/ijerph17051729

13. Czeisler M, Tynan MA, Howard ME, Honeycutt S, Fulmer EB, Kidder DP, Robbins R, Barger LK, Facer-Childs ER, Baldwin G, Rajaratnam SMW, Czeisler CA (2020) Public attitudes, behaviors, and beliefs related to COVID-19, stay-at-home orders, nonessential business closures, and public health guidance - United States, New York City, and Los Angeles, May 5-12, 2020. MMWR Morb Mortal Wkly Rep 69(24):751-758. https://doi.org/10.15585/ mmwr.mm6924e1

14. Dai M, Liu D, Liu M, Zhou F, Li G, Chen Z, Zhang Z, You H, Wu $\mathrm{M}$, Zheng Q, Xiong Y, Xiong H, Wang C, Chen C, Xiong F, Zhang Y, Peng Y, Ge S, Zhen B, Yu T, Wang L, Wang H, Liu Y, Chen Y, Mei J, Gao X, Li Z, Gan L, He C, Li Z, Shi Y, Qi Y, Yang J, Tenen DG, Chai L, Mucci LA, Santillana M, Cai H (2020) Patients with cancer appear more vulnerable to SARS-CoV-2: a multicenter study during the COVID-19 outbreak. Cancer Discov 10(6):783791. https://doi.org/10.1158/2159-8290.Cd-20-0422

15. Miyashita H, Mikami T, Chopra N, Yamada T, Chernyavsky S, Rizk D, Cruz C (2020) Do patients with cancer have a poorer prognosis of COVID-19? An experience in New York City. Ann Oncol. 31:1088-1089. https://doi.org/10.1016/j.annonc.2020.04. 006

16. Harris PA, Taylor R, Minor BL, Elliott V, Fernandez M, O'Neal L, McLeod L, Delacqua G, Delacqua F, Kirby J, Duda SN, Consortium RE (2019) The REDCap consortium: Building an international community of software platform partners. J Biomed Inform 95:103208. https://doi.org/10.1016/j.jbi.2019.103208
17. Harris PA, Taylor R, Thielke R, Payne J, Gonzalez N, Conde JG (2009) Research electronic data capture (REDCap)-a metadatadriven methodology and workflow process for providing translational research informatics support. J Biomed Inform 42(2):377381. https://doi.org/10.1016/j.jbi.2008.08.010

18. Karnofsky D (1977) Performance scale. Factors that influence the therapeutic response in cancer: a comprehensive treatise. Plenum Press, New York

19. Sangha O, Stucki G, Liang MH, Fossel AH, Katz JN (2003) The self-administered comorbidity questionnaire: a new method to assess comorbidity for clinical and health services research. Arthritis Rheum 49(2):156-163. https://doi.org/10.1002/art.10993

20. Tenforde MW, Billig Rose E, Lindsell CJ, Shapiro NI, Files DC, Gibbs KW, Prekker ME, Steingrub JS, Smithline HA, Gong MN, Aboodi MS, Exline MC, Henning DJ, Wilson JG, Khan A, Qadir N, Stubblefield WB, Patel MM, Self WH, Feldstein LR (2020) Characteristics of adult outpatients and inpatients with COVID-19 - 11 academic medical centers, United States, March-May 2020. MMWR Morb Mortal Wkly Rep 69(26):841-846. https://doi.org/ 10.15585/mmwr.mm6926e3

21. Papachristou N, Barnaghi P, Cooper B, Kober KM, Maguire R, Paul SM, Hammer M, Wright F, Armes J, Furlong EP, McCann L, Conley YP, Patiraki E, Katsaragakis S, Levine JD, Miaskowski C (2019) Network analysis of the multidimensional symptom experience of oncology. Sci Rep 9(1):2258. https://doi.org/10.1038/ s41598-018-36973-1

22. Ward Sullivan C, Leutwyler H, Dunn LB, Miaskowski C (2018) A review of the literature on symptom clusters in studies that included oncology patients receiving primary or adjuvant chemotherapy. J Clin Nurs 27(3-4):516-545. https://doi.org/10.1111/jocn. 14057

23. Lau J, Knudsen J, Jackson H, Wallach AB, Bouton M, Natsui S, Philippou C, Karim E, Silvestri DM, Avalone L, Zaurova M, Schatz D, Sun V, Chokshi DA (2020) Staying connected in the COVID-19 pandemic: telehealth at the largest safety-net system in the United States. Health Aff (Millwood):101377hlthaff202000903. doi: https://doi.org/10.1377/hlthaff.2020.00903

24. Al-Shamsi HO, Alhazzani W, Alhuraiji A, Coomes EA, Chemaly RF, Almuhanna M, Wolff RA, Ibrahim NK, Chua MLK, Hotte SJ, Meyers BM, Elfiki T, Curigliano G, Eng C, Grothey A, Xie C (2020) A practical approach to the management of cancer patients during the novel coronavirus disease 2019 (COVID-19) pandemic: An international collaborative group. Oncologist. 25:e936-e945. https://doi.org/10.1634/theoncologist.2020-0213

25. Gyawali B, Poudyal BS, Eisenhauer EA (2020) Covid-19 pandemic-an opportunity to reduce and eliminate low-value practices in oncology? JAMA Oncol. https://doi.org/10.1001/jamaoncol.2020. 2404

26. Ghosh J, Ganguly S, Mondal D, Pandey P, Dabkara D, Biswas B (2020) Perspective of oncology patients during COVID-19 pandemic: a prospective observational study from India. JCO Glob Oncol (6):844-851. https://doi.org/10.1200/go.20.00172

Publisher's note Springer Nature remains neutral with regard to jurisdictional claims in published maps and institutional affiliations. 